\title{
Modeling the enhanced-efficacy and curing-depth of photo-thermal dual polymerization in metal (Fe) polymer composites for 3D printing
}

\author{
Jui-Teng Lin ${ }^{1, *}$ Yi-Ze Lee ${ }^{2}$, Jacques Lalevee ${ }^{3}$, Chia-Hung Kao ${ }^{4}$, Kuan-Han Lin ${ }^{5}$, \\ and Da-Chuan Cheng, ${ }^{6, *}$ \\ 1 New Photon Corp., New Taipei City, Taiwan; jtlin55@gmail.com \\ 2 Department of Electrical and Engineering, National Taiwan University, Taipei, Taiwan; \\ r09941019@g.ntu.edu.tw \\ 3 Université de Haute-Alsace, CNRS, Mulhouse, France; jacques.lalevee@uha.fr \\ 4 Department of Nuclear Medicine and PET Center, China Medical University Hospital, \\ Taiwan; d10040@mail.cmuh.org.tw \\ 5 Department of Healthcare Adminstration, Asia University, Taiwan; \\ okonkwolin@asia.edu.tw \\ 6 Department of Biomedical Imaging and Radiological Science, China Medical University, \\ Taichung, Taiwan; dccheng@mail.cmu.edu.tw \\ *Correspondence: jtlin55@gmail.com ; and dccheng@mail.cmu.edu.tw
}

\begin{abstract}
This article presents, for the first time, the efficacy and curing depth analysis of photo-thermal dual polymerization in metal ( $\mathrm{Fe}$ ) polymer composites for $3 D$ printing of a 3-component $(A / B / M)$ system based on the proposed mechanism of our group, in which the co initiators A and B are Irgacure-369, and charge-transfer complexes (CTC), respectively; and the monomer M is TMPTA filled by Fe. Our formulas show the depth of curing $(Z c)$ is an increasing function of the light intensity, but a decreasing function of the Fe and photoinitiator concentrations. $Z c$ is enhanced by the additive [B] which produces extra thermal radical for polymerization under high temperature. The heat (or temperature) increase in the system has two components: (i) due to the light absorption of Fe filler, and (ii) heat released from the exothermic photopolymerization of the monomer. The heat is transported to the additive (or co-initiator) [B] to produce extra radical $R^{\prime}$ and enhance the monomer conversion function (CF). The CF has two opposite trends in their time profiles: (i) for small Fe concentration $(F)$, it is a time decaying function; and (ii) for large Fe, it is a time increasing profile. This switching feature predicted by our formula is also justified by our measured data. The Fe filler leads to temperature increase, but also limits the light penetration leading to lower $C F$ and $Z c$, which could be overcome by the additive initiator $[B]$ in thick polymers. the new finding of optimal Fe for maximal $C F$ and $Z c$ are explored theoretically.
\end{abstract}

Keywords: polymerization kinetics; monomer conversion; metal composited; enhancement effects; curing depth; $3 \mathrm{D}$ printing; addative manufacturing.

\section{Introduction}

To overcome the poor mechanical properties of pure polymers, metal polymer composites (MPCs) combine the functionalities of metals and the advantages of polymers have been proposed [1-7]. However, MPCs are still suffer some problems such as extremely poor metal-polymer compatibility, high metal filler content, and functional singularity [8-10].

Light emitting diodes (LED) photoinitiated polymerization offer many advantages such as its solvent-free formulation, mild conditions (ambient temperature, without monomer purification or stabilizers removal etc.), fast reaction rates, and in line with the green chemistry [11-15]. Copper complex photoredox catalyst photocatalyst have been reported by our group for free radical/cationic hybrid photopolymerization $[16,17]$. Nevertheless, very few polymeric composite containing metal fillers are prepared by the photopolymerization process due to the poor light penetration depth 
which also limits the curing dept. We have recently reported TMPTA as the model monomer, iron powder as filler and Irgacure 369 (Irg 369) as photoinitiator with the aid of two charge-transfer complexes (CTCs) as dual thermal/photochemical initiators uisng LED at $405 \mathrm{~nm}[18,19]$, in which the lack of light penetration was indirectly overcome with the help of CTC in association with heat release during the radical photopolymerization. In the dual thermal/photo polymerization process, we have sucessfully achieved 10 times more dpeth of curing than that of photopolymerization alone.

In supporting our recent measured data, Ma et al. [19], this article will present the kinetics, the conversion profiles features and the depth of curing of a 3-component $(\mathrm{A} / \mathrm{B} / \mathrm{M})$ system based on the proposed mechanism of our group [19]. We will demonstrate that the conversion function (CF) has two opposite trends in their time profiles depending on the amount of Fe. This switching feature predicted by our formula is also justified by our measured data. Analytic formulas for the $\mathrm{CF}$, depth of curing and heat (temperature) profiles will be derived rigorously.

\section{Methods and Modeling Systems}

\subsection{Photochemical Kinetics}

In association with the proposed scheme of of group, Ma et al [19], we propose in Fig. 1, a 3component system $(\mathrm{A} / \mathrm{B} / \mathrm{M})$ defined by the co initiators $[\mathrm{A}]$ and $[\mathrm{B}]$ with monomer $(\mathrm{M})$, in which the initiator $[\mathrm{A}]$ is excited to its first-excited state $\mathrm{A}^{*}$, and a triplet excited state $\mathrm{T}$ having a quantum yield (q). The triplet state $\mathrm{T}$ interacts with $[\mathrm{A}]$ to produce radical $(\mathrm{R})$ which couple with $\mathrm{M}$ for photopolymerization and release heat $(\mathrm{H})$. Additional heat $(\mathrm{H})$ is produced by the UV light absorption of the filler, iron mixed in the monomer. Heat is also produced by the light absorption of the iron filled in the monomer. The heat is transported to the additive (or co-initiator) [B] to produce extra radical R'. Therefore, the polymerization can be induced by the photo-radical $(R)$ and enhanced by the thermal-radical (R'). A specific measured system related to Fig. 1 was reported by Ma et al [19] for a 3-component system of PI/B/M, where PI is the photoinitiator Irgacure 369, B is a co-initiator of charge-transfer complex (CTC), and the $\mathrm{M}$ is the monomer rimethylolpropane triacrylate (TMPTA), which is filled with filler iron (Fe).

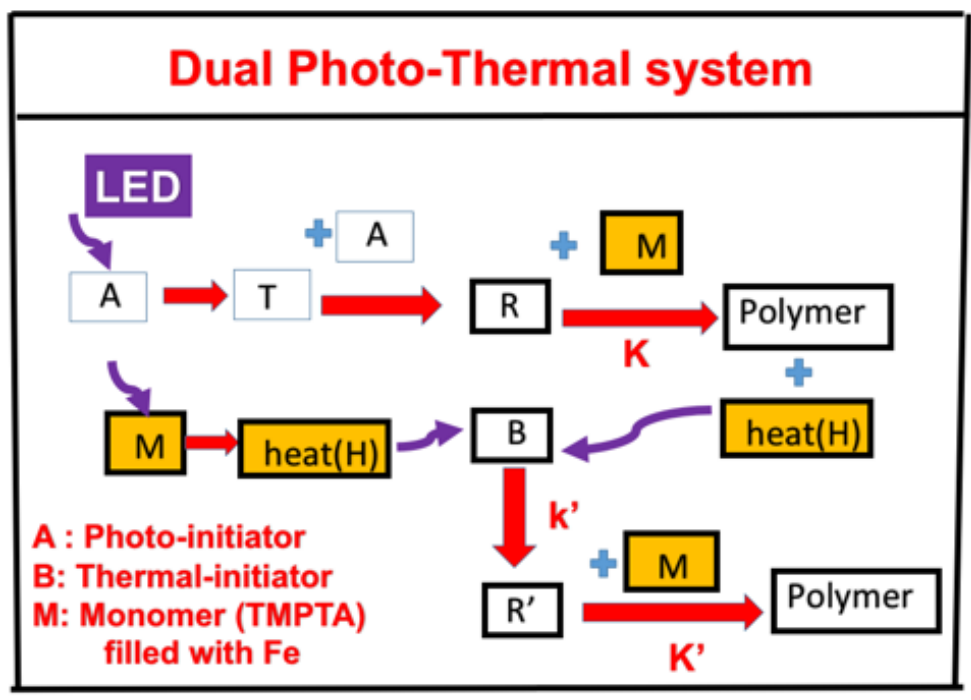

Fig. 1. The schematics of a dual function system, $(\mathrm{A} / \mathrm{B} / \mathrm{H})$, The heat $(\mathrm{H})$ can be produced by the light absorption of the iron filled in the monomer $(\mathrm{M})$ and the heat released by the photopolymerization, in which $\mathrm{R}$ and $\mathrm{R}$ ' lead to a photo-thermal dual polymerization (see text for more details).

The kinetic equations for our previous systems [20-23] are revised for the new system of Fig. 1 $(\mathrm{A} / \mathrm{B} / \mathrm{H} / \mathrm{M})$ as follows. We will use the short hand notations for the concentrations: $[\mathrm{A}]$ for photoinitiator Irgacure 369, [B] for the additive CTC, F for the filler iron (in wt\%), R and R' for the photo and thermal radical, respectively. 


$$
\begin{aligned}
& \frac{\mathrm{d}[\mathrm{A}]}{\mathrm{dt}}=-\mathrm{bI}[\mathrm{A}]+\mathrm{REG} \\
& \frac{\mathrm{d}[\mathrm{B}]}{\mathrm{dt}}=-\mathrm{k}^{\prime} \mathrm{H}[\mathrm{B}] \\
& \frac{\mathrm{dT}}{\mathrm{dt}}=\mathrm{bI}[\mathrm{A}]-\left(\mathrm{K}^{\prime \prime}+\mathrm{k}[\mathrm{A}]+\mathrm{k}^{\prime \prime} \mathrm{M}\right) \mathrm{T} \\
& \frac{\mathrm{dR}}{\mathrm{dt}}=\mathrm{k}[\mathrm{A}] \mathrm{T}-\mathrm{KMR}-\mathrm{VR}^{2} \\
& \frac{\mathrm{dR}}{\mathrm{dt}}=\mathrm{k}^{\prime} \mathrm{H}[\mathrm{B}]-\mathrm{K}^{\prime} \mathrm{MR}^{\prime}
\end{aligned}
$$

In Eq. (2) and (5), $\mathrm{H}$ is the heat (or temperature) in the monomer due to two components : (i) the $\operatorname{aFI}(z, t)$ term, due to light absorption of iron filler given by the absorption constant (a), light intensity (I) and iron concentration (F); and (ii) the heat released (the KMR term) from the exothermic photopolymerization of the monomer. Therefore, $\mathrm{H}$ is given by a generalized heat diffusion equation

$$
\frac{d H(z, t)}{d t}=a F I(z, t)+K M R+c \nabla^{2} H-b^{\prime} H
$$

where $b^{\prime}$ is the heat transport constant, the third term is the thermal conduction term in depth(z).

The UV light intensity has the depth (z) dependence due to the absorption of PI, [A], and iron filler (F) given by

$$
\frac{\mathrm{d}(\mathrm{z}, \mathrm{t})}{\mathrm{dz}}=-(\mathrm{b}[\mathrm{A}]+\mathrm{aF}) \mathrm{I}(\mathrm{z}, \mathrm{t})
$$

The monomer $(\mathrm{M})$ conversion rate equation has three components: triplet state $(\mathrm{T})$ direct coupling, and the radicals ( $R$ and $\left.R^{\prime}\right)$ produced by $[A]$ and $[B]$, respectively, given by

$$
\frac{\mathrm{dM}}{\mathrm{dt}}=-\left(\mathrm{k}^{\prime \prime} \mathrm{T}+\mathrm{KR}+\mathrm{K}^{\prime} \mathrm{R}^{\prime}\right) \mathrm{M}
$$

In Eq. (1) the regeneration (REG) term is given by REG=k"T+kM of the initiator; $b=83.6 a^{\prime} w q$, where $\mathrm{w}$ is the light wavelength (in $\mathrm{cm}$ ) and $\mathrm{q}$ is the triplet state T quantum yield; $\mathrm{a}^{\prime}$ is the mole absorption coefficient, in $(1 / \mathrm{mM} / \%)$ and $\mathrm{I}(\mathrm{z}, \mathrm{t})$ is the light intensity, in $\mathrm{mW} / \mathrm{cm}^{2}$. All the rate constants are defined previously [20-21] and they are related by the coupling terms. For examples, $\mathrm{k}$ " is for the couplings of $\mathrm{T}$ and $[\mathrm{M}] ; \mathrm{K}$ and $\mathrm{K}^{\prime}$ for the coupling of radicals $\mathrm{R}$ and $\mathrm{R}^{\prime}$ with monomer $\mathrm{M}$, respectively. $\mathrm{k}^{\prime} \mathrm{H}$ is the production rate of the thermal radical ( $\left.\mathrm{R}^{\prime}\right)$ from [B]. Here we have excluded the oxygen inhibition effect [22], and the couplings among $R$ and $R^{\prime}, T$ and $[B]$, which have not yet observed experimentally.

For comprehensive modeling we will use the so-called quasi-steady state assumption [20, 21]. The life time of the singlet and triplet states of photosensitizer, the triplet state $(\mathrm{T})$, and the radicals ( $R$ and $\left.R^{\prime}\right)$, since they either decay or react with cellular matrix immediately after they are created. Thus, one may set $d T / d t=d R / d t=d R^{\prime} / d t=0$, which give the quasi-steady-state solutions: $T=b I g[A]$, $\mathrm{R}^{\prime}=\mathrm{k}^{\prime} \mathrm{H}[\mathrm{B}] /\left(\mathrm{K}^{\prime} \mathrm{M}\right)$; and $\mathrm{g}=1 /\left(\mathrm{K}^{\prime \prime}+\mathrm{k}[\mathrm{A}]+\mathrm{k}^{\prime \prime} \mathrm{M}\right)$. Steady-state of $\mathrm{R}$ is much more complex due to the bimolecular term of $\mathrm{VR}^{2}$. We will consider the case of unimolecular, with $\mathrm{V}=0$ in Eq. (5) such that $\mathrm{R}=(\mathrm{k} / \mathrm{K}) \mathrm{bIg}[\mathrm{A}]$, and $\mathrm{KRM}=\mathrm{k}[\mathrm{A}] \mathrm{T}$ in Eq. (8).

Under the above quasi-steady-state solutions and for unimolecular case for $\mathrm{R}$, we obtain the simplified equations (with the thermal conduction term ignored) as follows.

$$
\begin{aligned}
& \frac{d[\mathrm{~A}]}{\mathrm{dt}}=-(\mathrm{bI}[\mathrm{A}]-\mathrm{REG}) \\
& \frac{\mathrm{d}[\mathrm{B}]}{\mathrm{dt}}=-\mathrm{k}^{\prime} \mathrm{H}[\mathrm{B}] \\
& \frac{\mathrm{dH}}{\mathrm{dt}}=\mathrm{aFI}+\mathrm{k}[\mathrm{A}] \mathrm{T}-\mathrm{b}^{\prime} \mathrm{H}
\end{aligned}
$$

The conversion efficacy $(\mathrm{CF})$ defined by $\mathrm{CF}=1-\mathrm{M}(\mathrm{t}) / \mathrm{M}_{0}$, with $\mathrm{M}(\mathrm{t})$ given by the solution of

$$
\frac{\mathrm{dM}}{\mathrm{dt}}=-\left(\mathrm{k}^{\prime \prime} \mathrm{TM}+\mathrm{k}[\mathrm{A}] \mathrm{T}\right)-\mathrm{k}^{\prime} \mathrm{H}[\mathrm{B}]
$$

\section{3.. Results and discussions}


A full numerical simulation is required for the solutions of Eq. (9) to (12), which will be presented elsewhere. We will focus on comprehensive analysis for special features and the key factors of dual radical enhancement for efficient conversion related to the measured data of Ma et al [19], based on the analytic formulas to be derived as follows.

\subsection{Analytic results}

In general, Eq. (11) and (12) require numerical simulation. For analytic formulas, we further approximate $\mathrm{g}=1 /(\mathrm{k}[\mathrm{A}])$, such that $\mathrm{T}=\mathrm{bI} /(\mathrm{k}[\mathrm{A}])$, Eq. (11) and (12) are reduced to

$$
\begin{aligned}
& \frac{\mathrm{dH}}{\mathrm{dt}}=[\mathrm{aF}+\mathrm{b}] \mathrm{I}(\mathrm{z}, \mathrm{t})-\mathrm{b}^{\prime} \mathrm{H} \\
& \frac{\mathrm{dM}}{\mathrm{dt}}=-\left(1+\left(\mathrm{k}^{\prime \prime} / \mathrm{k}\right) \mathrm{M} /[\mathrm{A}]\right) \mathrm{bI}(\mathrm{z}, \mathrm{t})-\mathrm{k}^{\prime} \mathrm{H}[\mathrm{B}]
\end{aligned}
$$

Analytic formulas need further assumption of RGE is taken as a mean reduction factor ( $\left.f^{\prime}\right)$, such that $b I[A]-R G E=f^{\prime} b I[A]$ having a value of $f^{\prime}=0$ to 1.0 . The first-order solution of Eq. (9) is given by $[A]=A_{0} \exp (-d t)$; with $d=b I(z)$, for $f^{\prime}=1$, and $I(z, t)$ assumed to be time-independent, that is the increase of $I(z, t)$ due to the depletion of $[A]$ is neglected. For the perfect recycle case, $f=0$, and $[A]=A_{0}$ is a constant. Using an average of $[A(z, t)]$ over $z$ and $t$ (defined as $A^{\prime}$ ), we obtain $I(z)=I_{0} \exp [-G z]$, with $\mathrm{G}=\mathrm{aF}+\mathrm{bA}^{\prime}$. The solution of Eq. (13) is given by an integral table

$$
H(z, t)=H_{0} \exp \left(-b^{\prime} t\right)+\left(d^{\prime} / b^{\prime}\right)\left[1-\exp \left(-b^{\prime} t\right)\right]
$$

where $\mathrm{H}_{0}$ is the initial value of $\mathrm{H}(\mathrm{t}=0)$, and $\mathrm{d}^{\prime}=(\mathrm{aF}+\mathrm{b}) \mathrm{I}(\mathrm{z})=(\mathrm{aF}+\mathrm{b}) \mathrm{I}_{0} \exp [-\mathrm{Gz}]$. We note that $\mathrm{H}(\mathrm{t}) \mathrm{has}$ a transient state value $\mathrm{H}_{0}\left(1-b^{\prime} t\right)+d^{\prime} t$, and a steady state value $(a F+b) I(z) / b^{\prime}$. Moreover, for $z>0, d^{\prime}$ has an optimal value at $\mathrm{F}=\mathrm{F}^{*}$, and it is a decreasing function of $\mathrm{F}$, for $\mathrm{F}>\mathrm{F}^{*}$. This optimal value is due to the competing term $(\mathrm{aF})$ in $\mathrm{d}^{\prime}=(\mathrm{aF}+\mathrm{b}) \mathrm{I}_{0} \exp \left[-\left(\mathrm{aF}+\mathrm{bA} \mathrm{A}^{\prime}\right)\right]$. Therefore, a higher $\mathrm{F}>\mathrm{F}^{*}$ and/or $\mathrm{A}^{\prime}$ leads to less light penetration due to the absorption factor $\mathrm{G}=\mathrm{aF}+\mathrm{bA} \mathrm{A}^{\prime}$ in $\mathrm{I}(\mathrm{z})=\mathrm{I}_{0} \exp [-\mathrm{Gz}$, and also leads to lower heat released (temperature) in the monomer, $\mathrm{H}(\mathrm{t})$.

Using Eq. (15) to solve for Eq. (10), we obtain

$$
[\mathrm{B}](\mathrm{z}, \mathrm{t})=\mathrm{B}_{0} \exp [-\mathrm{P}(\mathrm{t})]
$$

where $P(t)=k^{\prime}\left[t^{\prime} / b^{\prime}+d^{\prime \prime} Q(t)\right]$, with $d^{\prime \prime}=\left(H_{0}-d^{\prime} / b^{\prime}\right)$, and $Q(t)=\left[1-e x p\left(-b^{\prime} t\right)\right] / b^{\prime}$.

Using the first-order solution of Eq. (14), with $\mathrm{k}^{\prime} \mathrm{H}[\mathrm{B}]$ neglected, and for $[\mathrm{A}]=\mathrm{A}_{0} \exp (-\mathrm{dt})$, with $\mathrm{d}=\mathrm{bI}$, we find the second-order solution (including $\mathrm{k}$ 'HB]) of Eq. (14) given by

$$
M(t)=M_{0}-b I\left[t+\left(\left(k^{\prime \prime} / k\right) M_{0} / A_{0}\right) V(t)\right]-k^{\prime} B_{0}\left[\left(d^{\prime} / b^{\prime}\right) V^{\prime}(t)+d^{\prime \prime} V^{\prime \prime}(t)\right]
$$

where $V(t)=[1-\exp (-s t)] / s$, with $s=d+b I ; V^{\prime}(t)=[1-\exp (-q t)] / q$, with $q=k^{\prime}\left[d^{\prime} / b^{\prime}+d^{\prime \prime}\right]$; and $V^{\prime \prime}(t)=\left[1-\exp \left(-q^{\prime} t\right)\right] / q^{\prime}$, with $q^{\prime}=b^{\prime}+q^{\prime}$.

Two special cases are analyzed for Eq. (17) as follows.

(a) For steady-state: from Eq. (16), $V(t)=1 / s, V^{\prime}(t)=1 / q$, and $V^{\prime \prime}(t)=1 / q^{\prime} . M(t)$ is almost independent of the light intensity, we obtain the conversion efficacy $(C F)$ defined by $C F=1-M(t) / M_{0}$,

$$
\mathrm{CF}(\mathrm{z}, \mathrm{t})=\mathrm{bI}\left[\mathrm{t}+\left(\mathrm{k}^{\prime \prime} / \mathrm{k}\right) \mathrm{M}_{0} /(\mathrm{sA} 0)\right]+\mathrm{k}^{\prime} \mathrm{B}_{0}\left[\left(\mathrm{~d}^{\prime} / \mathrm{b}^{\prime}\right) / \mathrm{q}+\mathrm{d}^{\prime \prime} / \mathrm{q}^{\prime}\right]
$$

We note CF is proportional to the light dose (It) that this feature is only for the case of unimolecular termination of the radical $\mathrm{R}$ which is proportional to $(\mathrm{bI})$. For the case of bimolecular, $\mathrm{R}$ is proportional to the power of $(\mathrm{bI})^{0.5}$, and the steady-state value of CF is proportional to (bI) ${ }^{-0.5}$ [20].

(b) For transient state, $S(t)=S^{\prime}(t)=S^{\prime \prime}(t)=t$, we obtain the $C F$ 


$$
\mathrm{CF}(\mathrm{z}, \mathrm{t})=\mathrm{b}(\mathrm{It})\left[1 / \mathrm{M}_{0}+\mathrm{k}^{\prime \prime} /\left(\mathrm{kA}_{0}\right)\right]+\mathrm{k}^{\prime} \mathrm{t} \mathrm{B}_{0} \mathrm{H}_{0} / \mathrm{M}_{0}
$$

We note that Eq. (18) has 4 terms proportional to the light dose $E=I(z) t$, and initial concentrations $A$, and $\mathrm{B}_{0}, \mathrm{H}_{0}$ and the absorption constants, $\mathrm{b}$. However $\mathrm{CF}$ (for $\mathrm{z}>0$ ) is a decreasing function of Fe, since $\mathrm{I}(\mathrm{z})=\mathrm{I}_{0} \exp [-(\mathrm{aF}+\mathrm{bA}) \mathrm{z}]$.

\subsection{Depth of Curing (DoC)}

As shown by Eq. (7) the light intensity is an exponentially decreasing function of the depth(z) according to a Beer-Lambert law (BLL). However, for the situation of time-dependent intensity $\mathrm{I}(\mathrm{z}, \mathrm{t})$ due to the depletion of the PI concentration, $\mathrm{A}(\mathrm{t})=\mathrm{A} 0 \exp (-\mathrm{dt})$, a generalized BLL was developed by Lin [20], such that the solution of Eq. (8) becomes $I(z, t)=I_{0} \exp [-G z]$, in which $G$ is an average of $[A(z, t)]$ over $z$ and $t$ (defined as $A^{\prime}$ ), given by $\mathrm{G}=\mathrm{aF}+\mathrm{bA}$ '.

A curing depth $\left(Z_{c}\right)$ is defined by when the conversion efficacy is higher than a critical value, $\mathrm{CF}>\mathrm{C}^{*}$. Using $\mathrm{I}(\mathrm{z}, \mathrm{t})=\mathrm{I}_{0} \exp [-\mathrm{Gz}]$, and Eq. (18) for CF, we obtain

$$
\mathrm{Z}_{\mathrm{C}}=\ln \left[\left(\mathrm{SI}_{0}\right) /\left(C^{*}-\mathrm{S}^{\prime}\right)\right] /\left(a F+b A^{\prime}\right)
$$

where $\mathrm{S}=\mathrm{bt}\left[1 / \mathrm{M}_{0}+\mathrm{k}^{\prime \prime} /(\mathrm{kA} 0)\right] ;$ and the enhancement factor, $\mathrm{S}^{\prime}=\mathrm{k}^{\prime} \mathrm{t}\left(\mathrm{B}_{0} \mathrm{H}_{0}\right) / \mathrm{M}_{0}$.

We note that $Z_{c}$ is proportional to the light dose Iot, but it is a decreasing function of the effective absorption constant $\left(\mathrm{aF}+\mathrm{bA}^{\prime}\right)$, with $\mathrm{A}^{\prime}$ being the $\mathrm{z}$ and time -averaged PI concentration $[\mathrm{A}]$, given by $A^{\prime}$. Eq. (19) show that $Z c$ is enhanced by the additive [B] via $S^{\prime}=k^{\prime} t\left(B_{0} H_{0}\right) / M_{0}$, which is proportional to $\mathrm{k}^{\prime} \mathrm{B}_{0} \mathrm{H}_{0}$, i.e., the limited light penetration due to $\mathrm{Fe}$ is overcome by the additive $\mathrm{CTC}$, or [B]. Eq. (19) shows that $\mathrm{Zc}$ is proportional to $\ln \left(\mathrm{SI}_{0}\right)$ under the unimolecular case, with neglected $\mathrm{VR}^{2}$ term in Eq. (4). For the bimolecular dominant case (with $\mathrm{VR}^{2}>>\mathrm{KRM}$ ), Eq. (19) is revised to [21]

$$
\mathrm{Z}_{\mathrm{C}}=2 \ln \left[\mathrm{SI}_{0}^{0.5} /\left(C^{*}-\mathrm{S}^{\prime}\right)\right] /\left(a F+b A^{\prime}\right)
$$

We note that more detailed discussion and numerical results of $\mathrm{Zc}$ and curing time maybe found in our previous work [20,22].

As shown by Eq.(15), when Fe is too high the DoC is too low to create effective polymerization and it is limited to thin films. For lower Fe of $10 \%$ to $30 \%$, the DoC is larger than the sample thickness and sharp edges are produced. Moreover, high Fe leads to strong light absorption and the light dose is smaller than the polymerization threshold at certain sample depth.

\subsection{General features and new findings}

As shown by Eqs. (9) to (19), the following significant features of the $[A] /[B] / M$ system which was also proposed by Ma et al [23]). Our modeling has explored the follow general features, in which some new findings are not yet explored in our previous experiment of Ma et al \{23], but might be justified in our future works.

(i) As shown by Eq. (6), the heat (or temperature) increase in the system has two components: (a) the $\mathrm{aFI}(\mathrm{z}, \mathrm{t})$ term, due to light absorption of iron filler given by the absorption constant (a), light intensity (I) and iron concentration (F); and (b) the heat released (the KMR term) from the exothermic photopolymerization of the monomer.

(ii) The solution of heat $\mathrm{H}(\mathrm{t})$ given by Eq. (15) has two terms which has opposite trends in their time profiles; the first term is a decaying function, whereas the second term is an increasing profile. This switching feature maybe easily realized by Eq. (13), which has a zero slope when $\mathrm{F}=\mathrm{F}^{*}$ and $\left(a F^{*}+b\right) I(z)=b / H$. This new finding will be justified later by our measured data. We note that $H(t)$ has a transient state value $\mathrm{H}_{0}\left(1-b^{\prime} t\right)+d^{\prime} t$, and a steady state value $(a F+b) I / b^{\prime}$. Therefore, for $F>F^{*}$, higher $\mathrm{F}$ and/or $\mathrm{A}^{\prime}$ leads to less light penetration due to the term $\mathrm{G}=\mathrm{aF}+\mathrm{bA} \mathrm{A}^{\prime}$ in $\mathrm{I}(\mathrm{z})=\mathrm{I} 0 \exp [-\mathrm{Gz}]$, and lower heat released (temperature) in the monomer. This feature of optimalization is valid only for $z>0$. It does not exist for surface (with $\mathrm{z}=0$ ). 
(iii) As shown by Eq. (8) and (12), (14), the monomer conversion has 3 components: (a) from the direct coupling of $\mathrm{T}$ and $[\mathrm{A}],(\mathrm{b})$ the coupling of photon-radical (R) with $\mathrm{M}$, and (c) coupling of thermal-radical ( $\left.R^{\prime}\right)$ and $M$; in which $R^{\prime}$ is an enhancement radical produced from the co initiator, $[B]$, under a high temperature given by the heat function, $\mathrm{H}(\mathrm{t})$. We note that the Fe filler leads to temperature increase, but also limits the light penetration, leading to lower $\mathrm{CF}$ and $\mathrm{DoC}$, which could be overcame by the additive initiator [B] for thick samples.

(iv) As shown by Eq. (18) has 4 terms proportional to the light dose E=It, and initial concentrations $\mathrm{A}_{0}, \mathrm{~B}_{0}, \mathrm{H}_{0}$ and the absorption constants, $\mathrm{a}$ and $\mathrm{b}$ and the iron concentration $(\mathrm{F})$, the last term of Eq. (18), $d^{\prime} t=(a F+b) E / b '$. However, the $C F$ at steady-state is independent of the light intensity, i.e., low and high light intensity lead to the same saturated $\mathrm{CE}$, although high intensity has a faster rising profile. Above features are for the case with unimolecular coupling of KRM term in Eq. (4). For the situation of a strong bimolecular termination, we need to include the coupling of $\mathrm{VR}^{2}$ in Eq. (4), and leading a $\mathrm{CF}$ which is proportional to the (bI) ${ }^{0.5}$ (for transient state); and inverse proportional to (bI)-0.5 at steady-state, i.e., higher intensity leads to a lower steady-state CF than lower intensity. The enhancement factor is given by $S^{\prime}=k^{\prime} t\left(B_{0} H_{0}\right) / M_{0}$, shown in Eqs. (18) and (19).

(v) In this article, we assume that $\mathrm{k}^{\prime}$ is a rate constant. In general, one should revise it to $\mathrm{k}^{\prime}(\mathrm{H}-$ $\left.\mathrm{H}^{*}\right)$, such that a lower threshold radical temperature $\left(\mathrm{H}^{*}\right)$ of $[B]$ leads to a higher conversion rate.

(vi) As show by Eq. (19), the depth of curing (DoC), Zc, is an increasing function of the light intensity. However, there is an optimal $\mathrm{Zc}$, based on the parameter of $(\mathrm{aF}+\mathrm{b})$, i.e., there is an optimal value of the iron concentration (F) which can be found mathematically by taking the derivative of $\mathrm{Zc}$ over d', and let it equal 0 , which can be also found numerically [20]. This optimal value is due to the competing term in $\mathrm{d}^{\prime}=(\mathrm{aF}+\mathrm{b}) \mathrm{I}_{0} \exp \left[-\left(\mathrm{aF}+\mathrm{A}^{\prime}\right)\right]$. The enhanced $\mathrm{Zc}$ is given by $\mathrm{S}^{\prime}=\mathrm{k}^{\prime} \mathrm{t}\left(\mathrm{B}_{0} \mathrm{H}_{0}\right) / \mathrm{M}_{0}$. Eq. (19) also defines the minimal enhancement factor $\left(S^{*}\right)$ to reach a sample depth of $Z^{\prime}$ given by the condition of when $(\mathrm{aF}+\mathrm{b}) \mathrm{Z}^{\prime}>\ln \left(\mathrm{SI}_{0} /\left(\mathrm{C}^{*}-\mathrm{S}^{\prime}\right)\right.$, or $\mathrm{S}^{\prime}>\mathrm{S}^{*}$, with $\mathrm{S}^{*}=\mathrm{C}^{*}-\mathrm{SI} \mathrm{I}_{0} \exp \left[-(\mathrm{aF}+\mathrm{b}) \mathrm{Z}^{\prime}\right]$, or $\mathrm{k}^{\prime} \mathrm{t}\left(\mathrm{B}_{0} \mathrm{H}_{0}\right) / \mathrm{M}_{0}>\mathrm{C}^{*}-\mathrm{SI}_{0} \exp [-$ $\left.(\mathrm{aF}+\mathrm{b}) \mathrm{Z}^{\prime}\right]$.

(vii) Our modeling also shows that there is an optimal condition for the initiator PI concentration given by $\mathrm{d}(\mathrm{CF}) / \mathrm{dF}=0$, with $\mathrm{CF}$ given by Eq. (17), which also requires numerical stimulation [20].

\subsection{Theoretical predictions and future directions}

Based on our analytic formulas, Eq. (15), we show, in Fig. 2, the surface (at $z=0$ ) temperature profiles in the monomer in the absence of PI (with $b=0$ ), with heat produced by light absorption of Fe only. It shows that larger Fe mixed in the monomer leads to higher temperature profiles, for a given light intensity, and the saturation is due to the heat transport term, b'H. Fig.3 shows the temperature profiles in the presence of co-initiators, $[\mathrm{A}]$ and $[\mathrm{B}]$, with $(\mathrm{aF}+\mathrm{b}) \mathrm{I}_{0}=(0,0.5,1.0,1.2)(1 / \mathrm{sec})$, with initial temperature released from monomer conversion $\mathrm{H}_{0}=200{ }^{\circ} \mathrm{C}$, which decreases due to heat transported to the additive $[\mathrm{B}]$, but compensated by the heat produced by light absorption of Fe. It demonstrates the switching feature that higher Fe leads to a reversed temperature profile from a decaying to an increasing profile, at a transition value of about $(\mathrm{aF}+\mathrm{b}) \mathrm{I}_{0}=1.0(1 / \mathrm{sec})$.

Based on our formula, Eq. (19), we also show, in Fig. 5, the DoC $(\mathrm{Zc})$ as the function of various parameters. Fig 4(A) shows that $Z_{c}$ is an increasing function of $S^{\prime}$, the enhancement factor given by $S^{\prime}$ $=\mathrm{k}^{\prime} \mathrm{t}\left(\mathrm{B}_{0} \mathrm{H}_{0}\right) / \mathrm{M}_{0}$, for a given curing threshold $\mathrm{C}^{*}=0.4$, and fixed $\mathrm{SI}_{0}=0.7, \mathrm{aF}+\mathrm{bA} A^{\prime}=1.0$. Fig. $5(\mathrm{~B})$ shows that $\mathrm{Zc}$ is a decreasing function of the factor $\left(\mathrm{aF}+\mathrm{bA}^{\prime}\right)$, Fig.5(C) shows that $\mathrm{Zc}$ is an increasing function of $\mathrm{SI}$, which is proportional to the light dose $\mathrm{tI}_{0}$, and the coupling constant, $\mathrm{b}$, as shown by Eq. (19).

Fig. 4 shows the optimal feature of the absorption factor, $(\mathrm{aF}+\mathrm{b})$, for a maximal heat produced by the light absorption of $\mathrm{Fe}$, based on Eq. (15). The optimal feature exists only for $\mathrm{z}>0$, due to the light intenisty given by $\mathrm{I}(\mathrm{z}, \mathrm{t})=\mathrm{I}_{0} \exp (-\mathrm{Gz})$, with $\mathrm{G}=\mathrm{aF}+\mathrm{bA}$, which is a strong decraesing function of $\left(\mathrm{aF}+\mathrm{bA} A^{\prime}\right)$, for $\mathrm{z}>0$. These features are show in Fig.4, for $\mathrm{z}=(0,0.4,0.5,0.6) \mathrm{cm}$.

Based on our modleing predictions described above, we propose to conduct the following new measurements, whcih are not yet explored in Ref. [24].

(i) CF profiles for various initiator concentrations, $A_{0}$ and $B_{0}$, to justify our predicted enhancement factor give by $S$, in Eq. (15) and (19). 
(ii) CF profiles for various light intensity $\left(\mathrm{I}_{0}\right)$ to justify the steady-state $\mathrm{CF}$ scaling law of $\left(\mathrm{bI}_{0}\right)^{\mathrm{m}}$, with $\mathrm{m}=1.0$ and -0.5 ;

(iii) curing depth $(\mathrm{Zc})$ for various enhanced factor given by $S^{\prime}=k^{\prime} t\left(B_{0} H_{0}\right) / M_{0}$, as shown by Fig. 5 .

(iv) the optimal feature shown by Fig. 4 , for various $\mathrm{aFI}_{0}$, for a maximal heat produced by the light absorption of Fe.

Besides the enhancement effects discussed in the present article using an additive of CTC, there are many other strategies have been reported by our group, including the use of multi-wavelength light and strategies of reduction the oxygen inhibition [23-27]. A critical review for photopolymerization for 3D bioprinting can be found in Ref. [23].

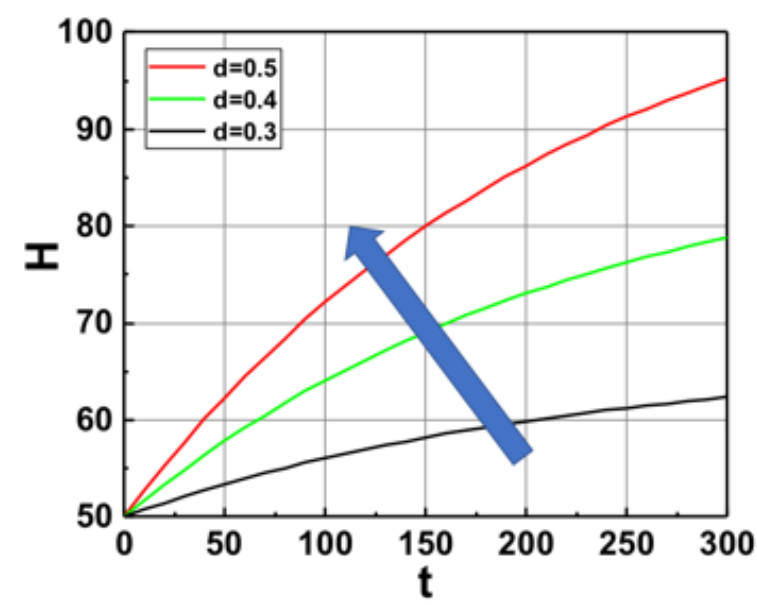

Fig. 2 The calculated surface temperature (at $z=0$ ) profiles of monomer based on Eq. (15) for various weight concentration of $\mathrm{Fe}$, with $\mathrm{aFI}=(0.3,0.4,0.5)(1 / \mathrm{sec})$ and $b^{\prime}=0.0045(1 / \mathrm{s})$, in the absence of PI (with $b=0)$, with heat produced by light absorption of Fe only, with $\mathrm{H}_{0}=50{ }^{\circ} \mathrm{C}$.

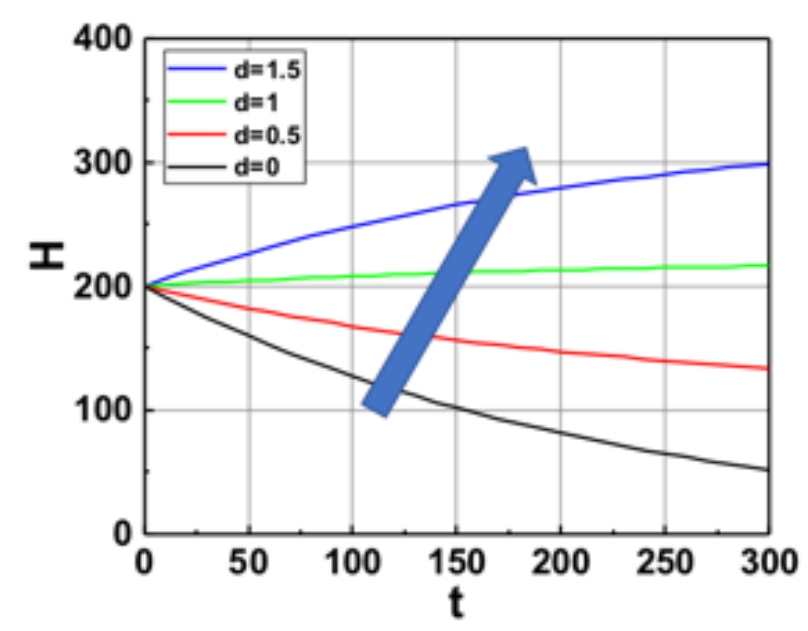

Fig. 3 Same as Fig. 2, but in the presence of co-initiators, $[A]$ and $[B]$. with $(a F+b) I_{0}=(0,0.5,1.0$, 1.5) $(1 / \mathrm{sec})$, with initial released heat from monomer conversion $\mathrm{H}_{0}=200{ }^{\circ} \mathrm{C}$, which decreases due to heat transported to the additive [B], but compensated by the heat produced by light absorption of Fe. 


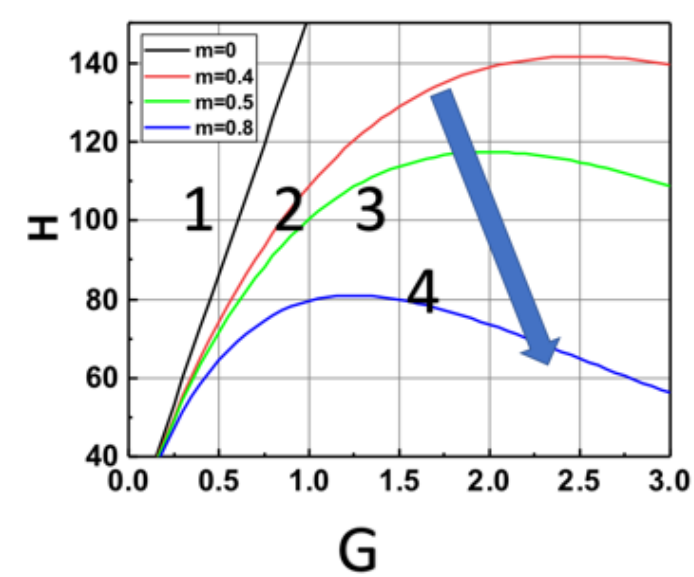

Fig. 4 The calculated temperature of monomer based on Eq. (15) for various absorption $\mathrm{G}=\mathrm{aF}+$ $\mathrm{bA}^{\prime}$, for $\mathrm{z}=(0,0.4,0.5,0.6) \mathrm{cm}$, for curves $(1,2,3,4)$, at $\mathrm{t}=200 \mathrm{sec}$.

(A)

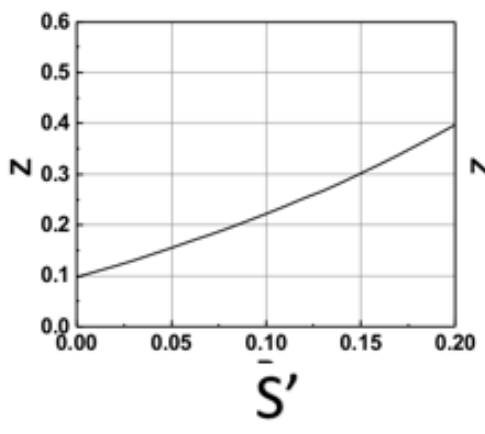

(B)

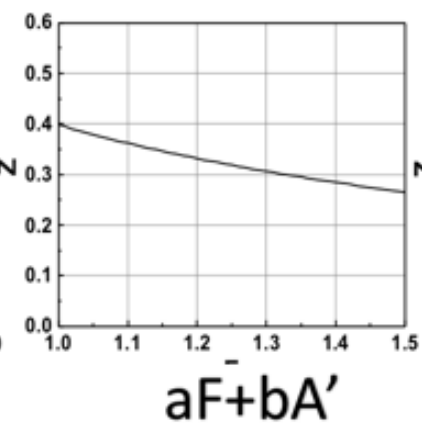

(C)

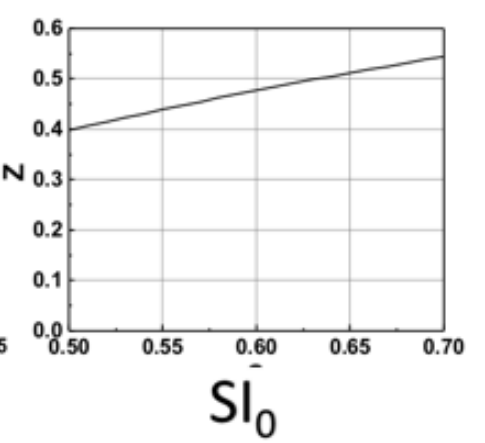

Fig. 5 The calculated $\operatorname{DoC}\left(Z_{c}\right)$ based on Eq. (19) for various parameters: (A) for Zc vs $S^{\prime}$ with fixed $\mathrm{SI}_{0}=0.7, \mathrm{aF}+\mathrm{bA}^{\prime}=1.0$ and $\mathrm{C}^{*}=0.4 ;(\mathrm{B})$ for $\mathrm{Zc}$ vs $\mathrm{aF}+\mathrm{bA}^{\prime}$, with fixed $\mathrm{SI}_{0}=0.5$ and $\mathrm{S}^{\prime}=0.5$; $(\mathrm{C})$ for $\mathrm{Zc}$ vs $\mathrm{SI}_{0}=0.5$, with fixed and $\mathrm{S}^{\prime}=0.2$ and $\mathrm{aF}+\mathrm{bA}^{\prime}=1.0$.

\subsection{Analysis of measured data}

The measured data are shown in Fig. 6 of our group, Ma et al [19], in which a PI Irgacure 369 is exposured to a LED at $405 \mathrm{~nm}\left(0.11 \mathrm{~W} \mathrm{~cm}^{-2}\right)$ for various iron (Fe) concentrations.

Fig. 6 (A) shows the measured conversion profiles of TMPDA for various Fe concentrations. These profiles can be analyzed by our CF shown in Eq. (18), which shows a typical saturation profile defined by $Q^{\prime}(t)=\left[1-\exp \left(-b^{\prime} t\right)\right] / b^{\prime}$ in Eq. (17).

Fig. 6 (B) shows the measured DoC for various Fe concentrations. These profiles can be analyzed by our Zc shown in Eq. (19), which shows Zc is an increasing function of the light intensity Io, but a decreasing function of the Fe $(\mathrm{F})$ and PI concentration $\left(\mathrm{A}^{\prime}\right)$, shown by the term (aF+bA'). The DoC is enhanced by the additive [B] via the $S$ function which is proportional to (bt) $\left[\left(1 / M_{0}-A_{0}\right)+\right.$ $\left.\mathrm{k}^{\prime} \mathrm{B}_{0} /\left(\mathrm{b}^{\prime} \mathrm{M}_{0}\right)\right]$. Our measured data had yielded (10 times) thick composites under the same dose using a LED irradiation at $405 \mathrm{~nm}$.

Fig. 6 (C) shows the temperature profiles in the absence of PI. They are related to the Eq. (13) and (15) with $b=0$, but $b^{\prime}>0$.

Fig. 6 (D) shows the temperature profiles for various Fe concentrations. These profiles can be analyzed by Eq. (15), which shows that $H(t)$ has a transient state value $H_{0}\left(1-b^{\prime} t\right)+d ' t$, and a steady state value $d^{\prime} / b^{\prime}$, with $d^{\prime}=(a F+b) I(z)$, with $I(z)=I_{0} \exp [-G z]$. Therefore, higher $F$ and/or A' leads to less light penetration due to the absorption factor $\mathrm{G}=\mathrm{aF}+\mathrm{bA}$ ', and also leads to a lower heat released (temperature) in the monomer, as shown by the measure curves of Fig. 6 (D). Furthermore, the 
transient profiles given by two terms having opposite trends in their time profiles: (a) for small $(\mathrm{aF}+\mathrm{b}) \mathrm{I}<<\mathrm{H}_{0}$, the first term is dominant and given by a decaying function given by $\mathrm{H}_{0} \exp \left(-\mathrm{b}^{\prime} \mathrm{t}\right) ;(\mathrm{b})$ for large $\mathrm{F}$ with $(\mathrm{aF}+\mathrm{b}) \mathrm{I}(\mathrm{z})>>\mathrm{H}_{0}$, the second term is dominant and given by an opposite, time increasing profile, given by $(a F+b) I(z)\left[1-\exp \left(-b^{\prime} t\right)\right]$. The switching profile from a time decaying one (for small F) to a time growing profile (for large F) are also shown by the measured curves of Fig. 2(D). This is a rather surprising feature predicted by our formula and justified by our measured data in Ma et al [19]. Our formulas also predict the switching value of $\mathrm{F}=\mathrm{F}^{*}$, when $\left(\mathrm{aF}^{*}+\mathrm{b}\right) \mathrm{I}(\mathrm{z})-\mathrm{bH}$.

We found that $\mathrm{wt} 10 \%$ and $\mathrm{wt} 30 \%$ Fe filler resin can achieve perfect three-dimensional structure, as shown in Fig. 7A and B, with great spatial resolution for the photoproducts in the presence of the iron fillers. However, when the content of iron keeps up to $50 \% \mathrm{wt} \%$, the pattern was not flat and some area under irradiation wasn't be fabricated (Fig. 7C). See more detailed of measurement method in Ref. [19].
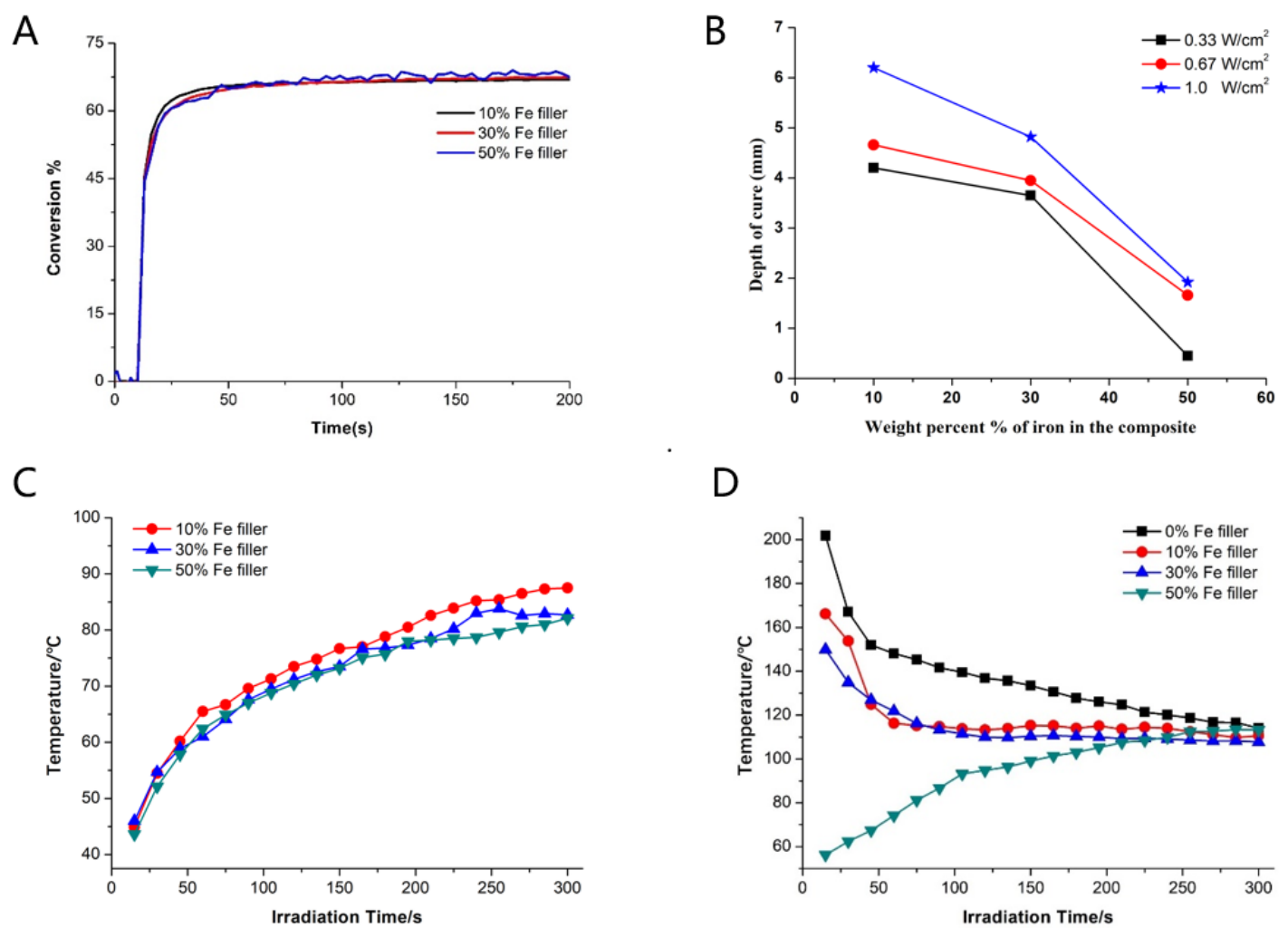

Fig. 6 (A) Measured photopolymerization profiles of TMPTA in laminate ( $25 \mu \mathrm{m}$ thickness) initiated by Irgacure 369 upon exposure to LED@405 nm in the presence of Fe filler with different contents (wt\%); (B) DoC results for the iron filler-based composites under the irradiation of high power LED@405 $\mathrm{nm}\left(0.33 \mathrm{~W} \mathrm{~cm}^{-2} ; 0.67 \mathrm{~W} \mathrm{~cm}^{-2} ; 1.0 \mathrm{~W} \mathrm{~cm}^{-2}\right)$; (C) temperature profiles of TMPTA with various $w t \%$ Fe in the absence of Irgacure 369; (D) temperature profiles of TMPTA with various $w t \%$ Fe in the presence of Irgacure $369\left(2.5 \times 10^{-5} \mathrm{~mol} \mathrm{~g}^{-1} \mathrm{TMPTA}\right)$. After Ma et al [19].

A

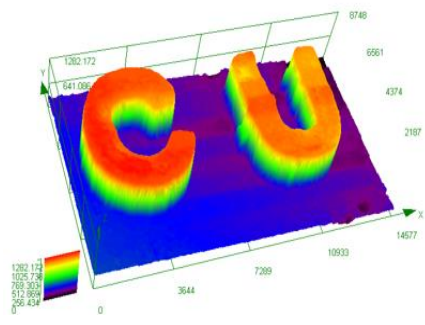

B

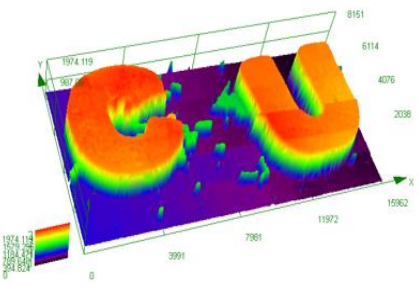

C

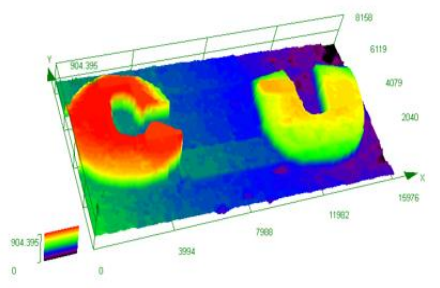


Fig. 7. Optical microscopy of the 3D patterns printed from TMPTA containing: (A) $10 \% \mathrm{wt} \%$, (B) $30 \% \mathrm{wt} \%$, and (C) $50 \% \mathrm{wt} \%$ content of iron filler; All printing experiments were performed with $5.5^{*} 10^{-5} \mathrm{~mol} / \mathrm{g}$ CTC(EMIM) in TMPTA. The scale bar is $2000 \mu \mathrm{m}$. After Ma et al [19].

\section{Conclusions}

We have demonstrated theoretically and justified by measured CF profiles of a 3-component $(\mathrm{A} / \mathrm{B} / \mathrm{M})$ system based on the proposed mechanism of our group, Ma et al [19], in which the co initiators are A, Irgacure 369, and B, charge-transfer complexes (CTC), and the monomer $\mathrm{M}$ is TMPDA. Our formula show the depth of curing $(Z c)$ is an increasing function of the light intensity, but a decreasing function of the Fe and photoinitiator concentration. $\mathrm{Zc}$ is enhanced by the additive [B] which produces extra thermal radical for polymerization under high temperature. The heat (or temperature) increase in the system has two components: due to light absorption of iron filler, and heat released from the exothermic photopolymerization of the monomer. The heat is transported to the additive (or co-initiator) [B] to produce extra radical $\mathrm{R}^{\prime}$ and enhance the monomer conversion function $(\mathrm{CF})$. For small Fe concentration $(\mathrm{F})$, the $\mathrm{CF}$ is given by a decaying function; whereas for large $\mathrm{F}$, it is given by a time increasing profile, The switching profile from a time decaying one (for small F) to a time growing profile (for large F) were also shown by the measured curves of Fig. 2(D). This is a rather surprising feature predicted by our formula and justified by our measured data.

]

Author contributions: Conceptualization, Jui-Teng Lin and Jacques Lalevee; Data curation, YiZe Lee, Chia-Hun Kao, Kuan-Han Lin and Da-Chun Cheng; Formal analysis, Jui-Teng Lin; Funding acquisition, Da-Chun Cheng; Investigation, Jacques Lalevee, Chia-Hun Kao, Kuan-Han Lin and DaChun Cheng; Methodology, Jui-Teng Lin and Yi-Ze Lee; Project administration, Jacques Lalevee and Da-Chun Cheng; Software, Yi-Ze Lee; Supervision, Da-Chun Cheng; Validation, Jacques Lalevee and Da-Chun Cheng; Writing - original draft, Jui-Teng Lin; Writing - review \& editing, Jui-Teng Lin.

Acknowledgments: JTL thanks the internal grant of New Photon Corp. JL thanks the the Aix Marseille University and The Centre 55 National de la Recherche (CNRS) for financial support. DCC thanks the financial support from CMU110-ASIA-11.

Conflicts of Interest: JT Lin is the CEO of New Photon Corp.

\section{References}

1. Patel, D.K.; Sakhaei, A.H.; Layani, M.; et al. Highly Stretchable and UV Curable Elastomers for Digital Light Processing Based 3D Printing, Adv. Mater. 29(15) (2017) 1606000.

2. Narupai, B.; Nelson, A. 100th Anniversary of Macromolecular Science Viewpoint: Macromolecular Materials for Additive Manufacturing, ACS Macro Letters 9(5) (2020) 627-638.

3. Xu, Z.; Gao, C.; In situ Polymerization Approach to Graphene-Reinforced Nylon-6 Composites, Macromolecules 43(16) (2010) 6716-6723.

4. Zhang, Y.; Josien, L.; Salomon, J.P.; Simon-Masseron, A,; Lalevée, J. Photopolymerization of Zeolite/Polymer-Based Composites: toward 3D and 4D Printing Applications, ACS Applied Polymer Materials 3(1) (2021) 400-409.

5. Zhang, Y.; Josien, L.; Salomon, J.P.; Simon-Masseron, A,; Lalevée, J. Radical photoinitiation with LEDs and applications in the 3D printing of composites, Chem. Soc. Rev. 50(6) (2021) 3824-3841.

6. Liu, Y.; Lin, Y.; Jiao, T.; Lu, G.; Liu, J. Photocurable modification of inorganic fillers and their application in photopolymers for 3D printing, Polym. Chem. 10(46) (2019) 6350-6359.

7. Y. Xin, H. Peng, J. Xu, J. Zhang, Ultrauniform Embedded Liquid Metal in Sulfur Polymers for Recyclable, Conductive, and Self-Healable Materials, Adv. Funct. Mater. 29(17) (2019) 1808989.

8. Lei, Z.; Wu, P. A supramolecular biomimetic skin combining a wide spectrum of mechanical properties and multiple sensory capabilities, Nature Communications 9(1) (2018) 1134.

9. Chortos, A,; Liu, J.; Bao, Z. Pursuing prosthetic electronic skin, Nature Materials 15(9) (2016) 937-950. 
10. S. Dadashi-Silab, S. Doran, Y. Yagci, Photoinduced Electron Transfer Reactions for Macromolecular Syntheses, Chem. Rev. 116(17) (2016) 10212-10275.

11. Corrigan, N. Yeow, J.; Judzewitsch, P. Xu, J.; Boyer, C. Seeing the Light: Advancing Materials Chemistry through Photopolymerization, Angew Chem Int Ed Engl 58(16) (2019) 5170-5189.

12. Garra, P.; Caron, A.; Mousawi, A.; Graff, B.; Morlet-Savary, B. et al. Photochemical, Thermal Free Radical, and Cationic Polymerizations Promoted by Charge Transfer Complexes: Simple Strategy for the Fabrication of Thick Composites, Macromolecules 51(19) (2018) 7872-7880.

13. Garra, P.; Dietin, F.; Morlet-Savary, B; Dumur, F. et al. Photopolymerization processes of thick films and in shadow areas: a review for the access to composites, Polym. Chem. 8(46) (2017) 70887101.

14. Xu, Y.; Ding, Z.; Zhu, H.; Zhang, Y.; Knopf, S.; Xiao, P.; Lalevée, J. Preparation of Iron Filler-Based Photocomposites and Application in 3D Printing, Macromolecular Materials and Engineering 306(3) (2021) 2000720.

15. Garra, P.; Dietin, F.; Morlet-Savary, B; Dumur, F. et al. Charge Transfer Complexes as Pan-Scaled Photoinitiating Systems: From $50 \mu \mathrm{m}$ 3D Printed Polymers at $405 \mathrm{~nm}$ to Extremely Deep Photopolymerization (31 cm), Macromolecules 51(1) (2018) 57-70.

16. Mokbel, H.; Anderson, D.; Plenderleith, R.; Dietlin, C. et al. Copper photoredox catalyst "G1": A new high performance photoinitiator for near-UV and visible LEDs. J. Polym. Chem. 2017, 8, 5580-5592.

17. Mokbel, H.; Anderson, D.; Plenderleith, R.; Dietlin, C. et al. Simultaneous initiation of radical and cationic polymerization reactions using the "G1" copper complex as photoredox catalyst: Applications of free radical/cationic hybrid photopolymerization in the composites and 3D printing fields. Prog. Org. Coat., 132, 50-61 (2019). DOI: 10.1016/j.porgcoat.2019.02.044

18. Ma, Q,; Liu, S.; Le Dot, M.; Mokbel, H. et al. Imidazole based dual photo/thermal initiators for highly efficient radical polymerization under air with a metal-free approach, Polym. Chem. 12(44) (2021) 6386-6391.

19. Ma, Q.; Zhang, Y.; Lunay, A.; Le Dot, M.; Liu, S.; Lalevée, J. How to overcome the light penetration issue in photopolymerization? An example for the preparation of high content ironcontaining opaque composites and application in 3D printing. Eurp Poly J. (in press).

20. J.T. Lin and D.C. Cheng. Modeling the efficacy profiles of UV-light activated corneal collagen crosslinking. PloS One. 2017;12:e0175002.

21. Lin, J.T. Efficacy S-formula and kinetics of oxygen-mediated (type-II) and non-oxygen-mediated (type-I) corneal cross-linking. Ophthalmology Research. 2018; 8(1): 1-11.

22. Lin, J.T.; Chen, K.T.; Cheng, D.C.; Liu, H.L. Modeling the efficacy of radical-mediated photopolymerization: the role of oxygen inhibition, viscosity and induction time. Front. Chem. 2019, 7:760. doi: 10.3389/fchem.2019.00760.

23. Lin, J.T.; Lalevee, J.; Cheng, D. C. A Critical Review for Synergic Kinetics and Strategies for Enhanced Photopolymerizations for 3D-Printing and Additive Manufacturing, Polymers 13(14) (2021).

24. Lin JT, Liu HW. Chen KT, Chiu YC, Cheng DC. Enhancing UV photopolymerization by a redlight pre-irradiation: kinetics and modeling strategies for reduced oxygen-inhibition. J Polymer Science, 2020, 58, 683-691, DOI:10.1002/pol.20190201.

25. Lin, J.T.; Chen, K.T.; Chang, P.K.; Cheng, D.C. Enhancing blue-light-initiated photopolymerization in a three-component system: kinetic and modeling of conversion strategies. J Polymer Research, 2021, 28:2.

26. Lin, J.; Chen, K.T.; Cheng, D.C,; Liu, H.W. Dual-wavelength (UV and blue) controlled photopolymerization confinement for 3D-printing: modeling and analysis of measurements. Polymers, 2019, 11, 1819.

27. Lin, J.T., Liu, H.W., Chen, K.T. Cheng, D.C. 3-wavelength (UV, blue, red) controlled photopolymerization: improved conversion and confinement in 3D-printing. IEEE Access, 2020, 8, 49353-49362. 